ting" (JAOA1989;89:780-782). Articles such as this not only provide valuable insight for the medical community, but they also heighten physician sensitivity and respect for the deaf patient.

For the past 10 years, my mother (who teaches the deaf), my hearing-impaired brother, and I have given lectures to students at the Philadelphia College of Osteopathic Medicine on understanding the deaf patient. These lectures have proved stimulating, prompting many students to study sign language.

Deafness encompasses more than hearing loss. Linguistic abilities are altered. Up to $25 \%$ of communication is lost. Because of this, the deaf person is misinformed and misunderstood, often treated as a second-class citizen. An invisible disability, impaired hearing is not readily recognized; therefore, the deaf person's needs go silently unaddressed.

The authors of this superb article have taken an important step in communicating the deaf patient's special needs and the ways in which physicians can meet them.

HARRIS ROSS, DO,

Vice President

American Osteopathic College of Rehabilitation and Medicine

Philadelphia, $\mathrm{Pa}$

\section{DO involvement key to our profession's future}

This letter was sent to Dr Marcelino Oliva, immediate past president of the AOA. Because it presents an important challenge to the profession, Dr Oliva agreed to share it with JAOA readers.
A disproportionate number of osteopathic hospitals face declining occupancy rates and financial difficulties. Meanwhile, the number of osteopathic medical graduates is at a record high. Where will these up-and-coming osteopathic physicians continue their medical training and practice the healing arts if the number of osteopathic hospitals and institutions continues to decline? The answer to this question rests with today's practicing DOs. We must take an active role in the changing healthcare system in the United States.

Government supported HMOs continue to mushroom. Yet, many of the newer HMOs, PPOs, and other closed panel healthcare programs exclude osteopathic physicians and hospitals. Furthermore, too many major insurance companies, labor groups, and large corporate entities do not receive input from local, state, or national osteopathic associations. It seems that individual osteopathic physicians practicing at the local level are not consulted either.

Over the years, I have been trying to remedy this problem. While serving as president of the Wayne County Osteopathic Association a few years ago, I sent a letter to the medical directors and directors of medical education of all the osteopathic hospitals along the Interstate 94 corridor, from Lake Michigan to Lake Erie. In that letter, I petitioned the individuals at these institutions to address the upcoming crisis in medical training programs. I asked if it would be possible to establish an osteopathic consortium or the like for this pur- pose. No one responded to my letter.

Because of my involvement in serving Detroit innercity residents, I was asked about 10 years ago to participate in the development of a statewide healthcare program for the Michigan Conference of Teamsters Health and Welfare Fund. At the time, I was the only osteopathic physician on this panel; I still serve in this capacity. I am also the medical director of the largest Teamsters clinic in Michigan. As such, I helped establish an affiliation between this clinic and an osteopathic hospital corporation to develop clinical rotations in family practice medicine and other specialties. Patients from this clinic are referred primarily to osteopathic specialists and hospitals.

In part, I believe my early and continued involvement in this program has enabled Michigan DOs to fully participate in the Plan A Teamster clinics statewide. As a result, hundreds of thousands of patients visit osteopathic physicans and hospitals in Michigan each year.

Every practicing osteopathic physician should become involved in similar healthcare groups in any way possible. For example, we can speak to community service organizations on health-related issues or donate our services to community health projects.

The opportunities available to today's osteopathic physiciansunlimited licensure, modern hospital facilities, outstanding medical training institutions - are the result of our forebearers' sacrifices. We must pass this hardwon legacy, which we inherited, 
to the present-day osteopathic medical students.

If we are lax in our commitment to our profession's continued viability, we will have failed not only the next generation of osteopathic physicians, but also our teaching institutions, our patients, ourselves, and our country. If we are prohibited from participating in private-sector healthcare programs, our licenses will be of little value.

The struggle to retain our practice privileges seems to have begun-again. If we lose this fight, the osteopathic medical philosophy could be lost forever.

RANDOLPHE ROULIER, DO

Chairman, Department of Surgery

Parkview Hospital

Toledo, Ohio

\section{Possible suprascapular nerve involvement in injured supraspinatus muscle}

\section{To the Editor:}

In the article "Shoulder pain and repetition strain injury to the supraspinatus muscle: Etiology and manipulative treatment"(JAOA 1989;89:1037-1045), Dr Jacobson and his colleagues did not indicate any possible involvement of the suprascapular nerve. Suprascapular nerve entrapment could cause symptoms similar to those mentioned in the article. Neurologic evaluation, including electromyography and a nerve conduction test, would prove diagnostically beneficial.

Similarly, a clinical test that anesthetically blocks the supras-

capular nerve and produces symptom relief would also be indicative.

With either diagnosis, osteopathic manipulative treatment would certainly be appropriate.

\section{JAMES H.CORETTI, DO \\ Director, \\ Work Fitness Clinic \\ Grand Rapids, Mich}

\section{Response:}

\section{To the Editor:}

Repetition strain injury of the supraspinatus muscle responds well to injection delivered at the trigger point. Dexamethasone acetate $(1.5 \mathrm{~mL})$ with Marcaine (1 $\mathrm{mL}$ ) injected by use of a 22gauge, 1.5-inch needle is effective. When such conservative care proves ineffective, or history and physical examination warrant it, further diagnostic studies are indicated.

Carpal tunnel syndrome and a herniated disc at C5 - C6 with osteophytic spurs and resultant spinal stenosis are examples of entrapment neuropathies that can cause a similar clinical picture. Results of neurologic examination, electromyography, and a nerve conduction test may be normal. In such instances, magnetic resonance imaging or contrastenhanced computed tomography, preceded by myelography, may be necessary.

Regarding the neurologic portion of Dr Coretti's letter, my colleagues and I consulted a boardcertified neurologist. In his opinion, injury to the suprascapular nerve would occur with a history of direct macrotrauma to this re- gion, such as a gunshot wound. Complete loss of external rotation and supraspinatus and infraspinatus muscle mass atrophy would occur. Finally, because of this nerve's deep anatomic location, electromyography and a nerve conduction test would be difficult and may produce inaccurate results.

EDWARD JACOBSON, DO Pinellas Park, Fla

\section{Correction to September JAOA}

On page 1148 of the article, "Child sexual abuse: A physician's introduction to historical and medical validation," by Martin A. Finkel, DO, there is an error in the text of the second bulleted point under the subheading "Sexually transmitted diseases." In the third sentence, JAOA inadvertently reversed the mediums used for Chlamydia and for Neisseria gonorrhoeae. The text should read:

For Chlamydia, only cell culture in a proper medium is appropriate. For Neisseria gonorrhoeae species identification, an appropriate medium such as modified Thayer-Martin in an enriched carbon dioxide environment should be used for specimen collection. 